\title{
Risk factors and complications following percutaneous endoscopic gastrostomy: A case series of 1041 patients
}

\author{
Hans-Jürgen Richter-Schrag MD ${ }^{1}$, Sabine Richter MD1, Olaf Ruthmann MD¹, \\ Manfred Olschewski MD², Ulrich Theodor Hopt MD ${ }^{1}$, Andreas Fischer MD ${ }^{1}$
}

H-J Richter-Schrag, S Richter, O Ruthmann, M Olschewski, UT Hopt, A Fischer. Risk factors and complications following percutaneous endoscopic gastrostomy: A case series of 1041 patients. Can J Gastroenterol 2011;25(4):201-206.

BACKGROUND: Most studies exclude patients with severe coagulation disorders or those taking anticoagulants when evaluating the outcomes of percutaneous endoscopic gastrostomy (PEG).

OBJECTIVE: To investigate complications and risk factors of PEG in a large clinical series including patients undergoing antiplatelet and anticoagulant therapy.

METHODS: During a six-year period, 1057 patients referred for PEG placement were prospectively audited for clinical outcome. Exclusion criteria and follow-up care were defined. Complications were defined as minor or severe. Uni- and multivariate analyses were used to evaluate 14 risk factors. No standardized antibiotic prophylaxis was given.

RESULTS: A total of 1041 patients (66\% male, 34\% female) with the following conditions underwent PEG: neurogenic dysphagia $(n=450)$, cancer $(n=385)$ and others $(n=206)$. No anticoagulants were administered to 351 patients, thrombosis prophylaxis was given to 348 while full therapeutic anticoagulation was received by 313 . No increased bleeding risk was associated with patients who had above-normal international normalized ratio values (OR 0.79 [95\% CI 0.08 to 7.64 ]; $\mathrm{P}=1.00$ ). The total infection rate was $20.5 \%$ in patients with malignant disease, and $5.5 \%$ in those with nonmalignant disease. Severe complications occurred in 19 patients (bleeding $0.5 \%$, peritonitis $1.3 \%$ ). Cirrhosis (OR 2.91 [95\% CI 1.31 to 6.54]; $\mathrm{P}=0.008$ ), cancer (OR 2.34 [95\% CI 1.33 to 4.12]; $\mathrm{P}=0.003$ ) and radiation therapy (OR 2.34 [95\% CI 1.35 to 4.05 ]; $\mathrm{P}=0.002$ ) were significant predictors of post-PEG infection. The 30 -day mortality rate was $5.8 \%$. There were no procedure-related deaths.

CONCLUSIONS: Cancer, cirrhosis and radiation therapy were predictors of infection. Post-PEG bleeding and other complications were rare events. Collectively, the data suggested that patients taking concurrent anticoagulants had no elevated risk of post-PEG bleeding.

Key Words: PEG anticoagulation; PEG bleeding risk; PEG complications; PEG risk factors; Percutaneous endoscopic gastrostomy

Dercutaneous endoscopic gastrostomy (PEG) using the pull-through 1 technique has become established in clinical practice for the maintenance of enteral feeding of patients with impaired swallowing and food passage due to cancer, neurological conditions or other diseases (1). Serious coagulation impairments, ethical issues (eg, artificial nutrition) and advanced liver cirrhosis with pronounced ascites are recognized guideline-relevant contraindications for PEG (1). According to the recommendations of the American Society for Gastrointestinal Endoscopy, thrombocyte aggregation inhibitors such as acetylsalicylic acid or ticlopidine are relative contraindications for PEG, while anticoagulants such as clopidogrel and phenprocoumon/warfarin make PEG a high-risk

\author{
Les facteurs de risque et les complications après \\ une gastrostomie endoscopique percutanée : \\ une série de cas de 1041 patients
}

\begin{abstract}
HISTORIQUE : Au moment d'évaluer les résultats de la gastrostomie endoscopique percutanée (GEP), la plupart des études excluent les patients ayant de graves troubles de la coagulation ou qui prennent des anticoagulants. OBJECTIF : Évaluer les complications et les facteurs de risque de la GEP dans une grande série clinique incluant des patients subissant un traitement antiplaquettaire et anticoagulant.
\end{abstract}

MÉTHODOLOGIE : Pendant une période de six ans, 1057 patients aiguillés en vue d'une GEP ont fait l'objet d'une vérification prospective de leurs résultats cliniques. Les auteurs ont défini les critères d'exclusion et les soins de suivi. Ils ont défini les complications comme mineures ou graves. Les analyses univariées et multivariées ont permis d'évaluer 14 facteurs de risque. Aucune prophylaxie antibiotique standardisée n'a été administrée. RÉSULTATS : Au total, 1041 patients (66\% d'hommes, $34 \%$ de femmes) ayant les troubles de santé suivants ont subi une GEP : dysphagie neurogène $(n=450)$, cancer $(n=385)$ et autres $(n=206)$. Trois cent cinquante et un patients n'ont reçu aucuns anticoagulants, mais 348 ont reçu une prophylaxie de la thrombose, et 313, une anticoagulothérapie complète. Aucun risque de saignement accru ne s'associait à des patients dont les valeurs de ratio normalisées internationales se situaient au-dessus de la normale (RRR 0,79 [95\% IC 0,08 à 7,64]; $\mathrm{P}=1,00$ ). Le taux d'infection total était de $20,5 \%$ chez les patients ayant une maladie maligne et de $5,5 \%$ chez ceux ayant une maladie non maligne. On a constaté de graves complications chez 19 patients (hémorragie $0,5 \%$, péritonite $1,3 \%$ ). La cirrhose (RRR 2,91 [95 \% IC 1,31 à 6,54]; $\mathrm{P}=0,008$ ), le cancer (RRR 2,34 [95 \% IC 1,33 à 4,12]; $\mathrm{P}=0,003$ ) et la radiothérapie (RRR 2,34 [95\% IC 1,35 à 4,05]; $\mathrm{P}=0,002$ ) étaient des prédicteurs significatifs d'infection après une GEP. Le taux de mortalité dans les 30 jours s'élevait à 5,8 \%. Il n'y avait aucun décès lié à l'intervention.

CONCLUSIONS : Le cancer, la cirrhose et la radiothérapie étaient des prédicteurs d'infection. L'hémorragie après la GEP et les complications étaient rares. Collectivement, les données indiquaient que les patients qui prenaient des anticoagulants concomitants ne présentaient pas de risque élevé d'hémorragie après la GEP.

procedure $(2,3)$. Due to the present lack of data, a therapy pause of seven to 10 days (for patients on clopidogrel or ticlopidine) or three to five days (for patients on phenprocoumon) is recommended before the procedure. Patients taking clopidogrel and acetylsalicylic acid should preferably be switched to acetylsalicylic acid monotherapy. Unfractionated heparin (UFH) should be withdrawn $4 \mathrm{~h}$ to $6 \mathrm{~h}$ before PEG.

The present study prospectively examined, among others, general and specific post-PEG bleeding complications in patients who were concurrently taking and not taking anticoagulants or antiplatelet drugs. It also determined whether the complications can be predicted by patients' general risk factors.

${ }^{1}$ Department of General and Visceral Surgery, University Hospital of Freiburg, Albert-Ludwigs University; ${ }^{2}$ Department of Medical Biometry and Statistics, University Medical Center Freiburg, Freiburg, Germany

Correspondence: Dr Hans-Jürgen Richter-Schrag, Department of General and Visceral Surgery, University Hospital of Freiburg, Hugstetter Strasse 55, D-79106 Freiburg im Breisgau, Germany. Telephone 49-761-270-2541 ext 42, fax 49-761-270-2775,

e-mail hans-juergen.schrag@uniklinik-freiburg.de

Received for publication December 8, 2009. Accepted October 12, 2010 


\begin{abstract}
Study design
A total of 1057 patients who underwent PEG placement according to a modified pull-through technique $(1,4)$ in the Department of General and Visceral Surgery at the General Hospital of the University of Freiburg (Freiburg, Germany) during a six-year period were included in the present study, which analyzed the possible risk factors for complications. Ambulatory PEG placements were not performed.

The following exclusion criteria were defined:

A. Patients in whom no standard 'pull-through' technique with or without preceding Savary-Gilliard dilation (SG-dilation) was possible due to stenosis of the hypopharynx or esophagus.

B. Patients in whom PEG could not be performed without additional imaging (computed tomography).

C. Patients in whom PEG placement had to be terminated prematurely due to respiratory or other complications.

D. Missing written consent.
\end{abstract}

In agreement with the European Society of Parenteral and Enteral Nutrition (ESPEN) guidelines (1), no standardized antibiotic prophylaxis was applied in the department. In stroke patients and patients on cardiosupportive apparatuses, thrombocyte aggregation inhibitors (eg, acetylsalicylic acid [Aspirin, Bayer Schering Pharma, Germany] or clopidogrel [Plavix, Bristol-Myers Sanofi Pharmaceuticals Partnership, USA]) were generally not discontinued before PEG, nor was treatment with unfractionated heparin (UFH; Liquemin, Hoffmann-La Roche Pharma AG, Germany). Phenprocoumon (Marcumar, Hoffmann-La Roche AG, Germany) was also not defined as a contraindication. Ascites were drained as much as possible during the PEG healing time (seven days). The observation period included the in-hospital time or, if hospitalization was less than one week ( $n=103)$, at least eight days. Furthermore, patients were followed up at scheduled intervals (annually) after discharge.

\section{Ethics}

As confirmed by the Ethics Commission of the University of Freiburg, the present study did not require approval. All treatments were undertaken for reasons of medical indication and no details were altered during the evaluation to accommodate study objectives during hospitalization. Declaration of consent from the patient or legal guardian was obtained $24 \mathrm{~h}$ before the procedure was performed.

\section{Data collection}

During the first eight days following PEG, daily ward rounds were performed by the endoscopic team to monitor complications. In cases for which hospitalization exceeded eight days, evaluation was performed by colleagues within the treating specialty ward at scheduled intervals (twice per week); complications were reported to the endoscopic team. A standardized worksheet was used to evaluate PEG complications such as post-PEG bleeding, peritonitis, infection and others. The risk factors examined are summarized in Table 1.

\section{Definition of complications}

Complications that occurred during hospitalization were divided into minor, severe and follow-up categories as follows:

Minor complications: Peristomal wound infection (reddening with secretion or secretion alone) and gastroparesis. The latter was defined as a persistent reflux of $500 \mathrm{~mL}$ or more.

Severe complications: Postprocedural bleeding (requiring or not requiring operation) and peritonitis. In clinically diagnosed peritonitis, the indication for surgery was, in principle, considered without further diagnostic evaluation.

Postprocedural bleeding was defined as the occurrence of at least one of the following: hematemesis or passing blood anally, or via the stoma or PEG tube.

Follow-up: Complications after discharge (buried bumper or blocked and/or leaking tubes). Direct or indirect complications such as cardiac and/or respiratory arrest, aspiration of gastric contents, acute respiratory distress syndrome or intestinal perforation causing death were defined as PEG-related mortality.
PEG technique

All PEG placements were performed by two consultants of the endoscopy department or under their supervision. Only propofol (Disoprivan, AstraZeneca AG, Switzerland) was used for sedation. Infiltration with local anesthetic is not a standard operating procedure in the department.

PEG tubes were placed using the pull-through technique described by Gauderer et al (4). In all cases, 15 Fr Freka PEG tubes (Fresenius Kobi AG, Germany) were used. The penetration trocar contained in the set was always replaced with a 20 -gauge, $0.9 \mathrm{~mm} \times 70 \mathrm{~mm}$ hypodermic needle (BL/LB, Braun Melsungen AG, Germany), in which the halved suture was threaded in a retrograde fashion. After skin disinfection of the left upper abdominal quadrant with 0.1 povidoneiodine solution (Braun Melsungen AG, Germany), PEG was performed using a one-hand technique - the examiner operated the endoscope with one hand while the skin incision and PEG penetration was made with the other. Care is taken to avoid penetration of the gastric wall while making the incision with a scalpel (No. 11, Feather Safety Razor Co Ltd, Japan). This technique can be performed equally well either fiber optically or with video assistance.

\section{Statistical analysis}

Data are presented as mean \pm SD with ranges for continuous variables, and absolute and relative frequencies for categorical variables. For comparisons of patients' baseline characteristics, the Fisher's exact test or $\chi^{2}$ test were performed. Univariate logistic regression analysis was used to estimate ORs and associated $95 \%$ CIs for possible risk factors with respect to complications. A multivariate analysis of risk factors was performed for infection, but was numerically not possible for bleeding and peritonitis due to the low numbers of events. All statistical tests were two-sided and used a significance level of 0.05. Data analysis was performed using SPSS 15.0 (IBM Corporation, USA).

\section{RESULTS}

\section{Perioperative data and group characteristics}

Excluded patients: Table 2 is an overview of the patients' characteristics and indications. Fifteen of 1057 patients (1.51\%) were excluded (study exclusion criteria B: missing impression or missing transillumination or positive aspiration test $[\mathrm{n}=11]$; criteria $C$ : respiratory insufficiency $[n=2]$, spontaneous tumour bleeding $[n=1]$ or undrainable ascites $[n=1])$. One patient died on the first postoperative day due to multiorgan failure.

\section{PEG technique}

The mean operation time was $4.5 \mathrm{~min}$ (range $3 \mathrm{~min}$ to $10 \mathrm{~min}$, from the beginning of the endoscopy to fixation of the outer fixator plate). The mean propofol dose was $85 \mathrm{mg}$ (range $40 \mathrm{mg}$ to $220 \mathrm{mg}$ ). Preoperative ascites drainage using pigtail catheters (12 Fr, Flexima, Boston Scientific, USA) was necessary in 30 cases. In 124 cases, a jejunal extension tube (Freka, Fresenius Kabi AG, Germany) was placed at the same time due to pre-existing gastroparesis or increased reflux quantities (more than $500 \mathrm{~mL} /$ day). Sixteen patients underwent dilation due to stenosis in the hypopharynx $(n=11)$ or the esophagus $(n=5)$ immediately before PEG. None of these patients were treated with anticoagulants.

\section{Pre-PEG treatment and therapeutic anticoagulation}

At the time of PEG, 480 patients were being treated with antibiotics: 356 for an existing aspiration pneumonia and 124 due to complications from underlying disease (naso-oropharyngeal and gastrointestinal infections, sepsis, pneumonias and endocarditis prophylaxis).

Neurological patients had 9.9 times higher risk of developing aspiration pneumonia before PEG placement than patients with other diseases (95\% CI 7.4 to $13.2 ; \mathrm{P}<0.001$ ). Nine of 36 patients with liver cirrhosis showed an abnormal international normalized ratio (INR) (mean INR in all patients without anticoagulants: $1.5 \pm 0.44$, range 1.2 to 2.6 ).

In patients who underwent PEG, 351 were not treated with anticoagulants, 348 were treated with low-molecular-weight heparin (LMWH; Clexane, Sanofi-Aventis, Germany) for thrombosis 
TABLE 1

Risk analysis of possible risk factors for postoperative complications

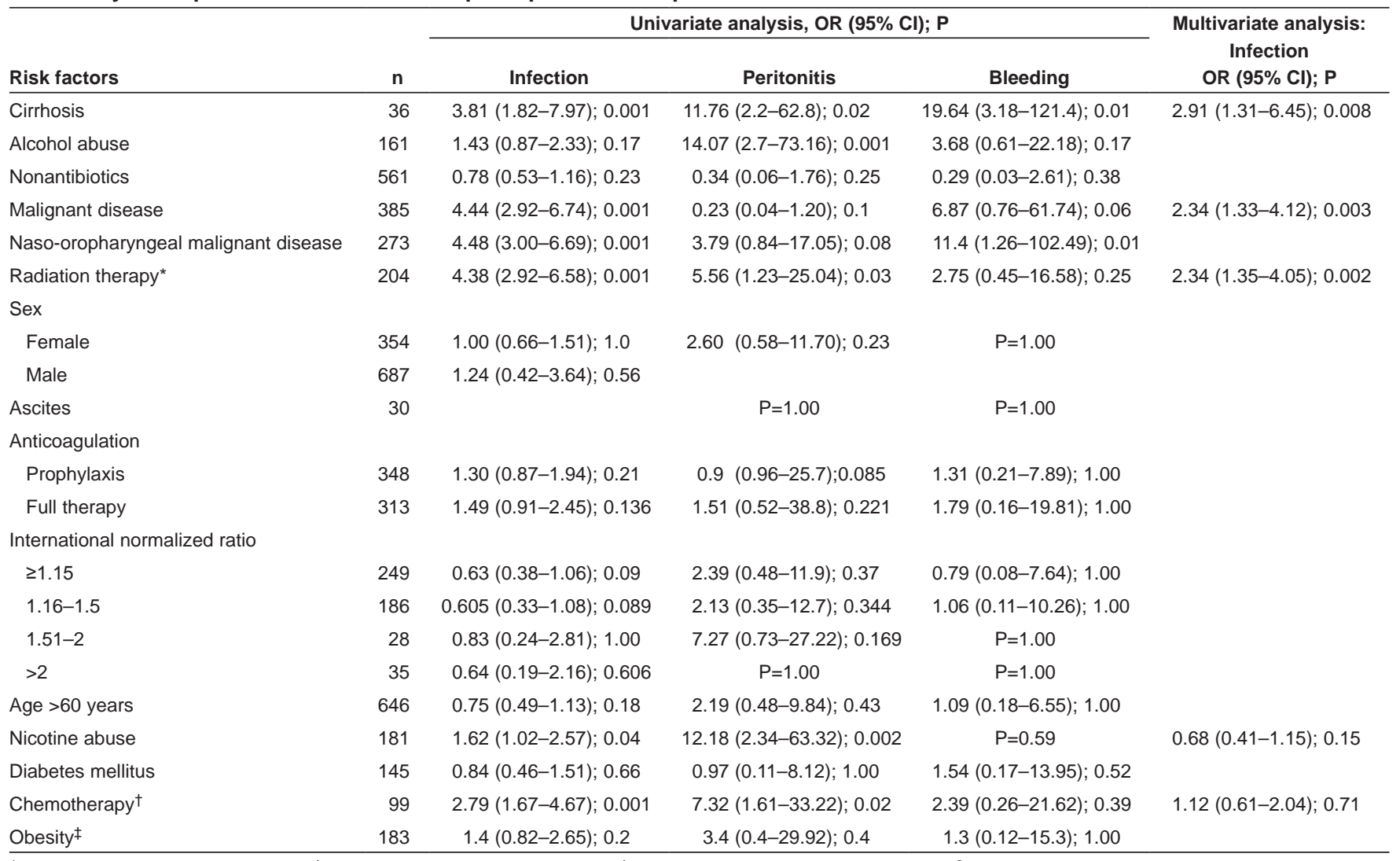

${ }^{*}$ Inclusive finished radiation ( $\left.\mathrm{n}=82\right) ;{ }^{\dagger}$ During percutaneous gastrostomy; ${ }^{\ddagger}$ Body mass index greater than $25 \mathrm{~kg} / \mathrm{m}^{2}$

TABLE 2

Patient characteristics

\begin{tabular}{|c|c|c|c|c|c|}
\hline & \multirow{2}{*}{$\begin{array}{l}\text { No anticoagulants } \\
(n=351)\end{array}$} & \multirow{2}{*}{$\begin{array}{l}\text { Thrombosis } \\
\text { prophylaxis }(n=348)\end{array}$} & \multicolumn{2}{|c|}{ Anticoagulants } & \multirow[b]{2}{*}{ Total } \\
\hline & & & $A(n=313)$ & $B(n=29)$ & \\
\hline \multicolumn{6}{|l|}{ Age, years, mean \pm SD (range) } \\
\hline Adult patients & $62 \pm 12.84(18-93)$ & $62 \pm 15.67(18-88)$ & $67 \pm 14.61(18-97)$ & $70.3 \pm 11.5(39-86)$ & $64 \pm 14.65(18-97)$ \\
\hline Pediatric patients & $5 \pm 4.46(0.4-14)$ & $15 \pm 4.35(3-17)$ & $13 \pm 5.56(5-17)$ & 0 & $7 \pm 6(0.4-17)$ \\
\hline \multicolumn{6}{|l|}{ Sex } \\
\hline Female & 119 & 112 & 111 & 12 & 354 \\
\hline Preoperative diabetes mellitus & 21 & 42 & 78 & 4 & 145 \\
\hline Alcohol abuse & 79 & 63 & 18 & 1 & 161 \\
\hline Cirrhosis & 17 & 14 & 5 & 0 & 36 \\
\hline Nicotine abuse & 85 & 58 & 29 & 9 & 181 \\
\hline Neurological diseases* & 50 & 151 & 233 & 16 & 450 \\
\hline Nonmalignant, non-neurological diseases ${ }^{\ddagger}$ & 102 & 56 & 43 & 5 & 206 \\
\hline High-risk conditions ${ }^{\S}$ & 12 & 19 & - & - & 78 \\
\hline Deceased & 145 & 148 & 105 & 9 & 407 \\
\hline
\end{tabular}

Data presented as $n$ unless otherwise indicated. *Insult (42.4\%), prolonged craniocerebral trauma with axonal shear injury (20.9\%), encephalitis (6\%); ${ }^{\dagger}$ Esophageal and ovarian carcinoma (17\%), naso-oropharyngeal carcinoma (41.5\%), jaw carcinoma (2.3\%), hypopharynx carcinoma (13.1\%), oropharyx carcinoma (16.6\%), larynx carcinoma (8.4\%), lip carcinoma (0.3\%), multilayer carcinomas (0.8\%); ${ }^{\ddagger}$ Heart attack (2.4\%), cardiac assist devices (5.8\%), multiorgan failure (17.4\%), pseudocysts of the pancreas (1.9\%), chronic inflammatory bowel disease (1.4\%), unclear dysphagia (6.3\%), developmental disorders due to different syndromes (34.4\%), psychiatric diseases (16.5\%), gastric outlet obstruction (14\%), Parkinson's disease (4.4\%), intracerebral bleeding (15.8\%), intracerebral abscess (0.4\%), thrombosis basilar/sinus venous thrombosis (4.4\%), epilepsy (5.7\%); ${ }^{\S}$ Defined by the American Society for Gastrorintestinal Endoscopy $(2,3)$ as a heart valve and thromboembolic complication, prolonged myocardial insufficiency with another episode of heart failure. A Full therapeutic anticoagulation; B Acetylsalicylic acid/ clopidogrel only 


\section{TABLE 3 \\ Complications following percutaneous endoscopic gastrostomy (PEG)}

\begin{tabular}{lc}
\hline Complications & \\
\hline Minor & \\
Local infection & $115(11.1)$ \\
$\quad$ Gastroparesis & $7(0.7)$ \\
Severe & \\
Post-PEG bleeding & $5(0.5)$ \\
Peritonitis & $14(1.3)$ \\
Follow up & $53(5.1)$ \\
Buried bumper, $\mathrm{n}$ & 21 \\
Leakage or blockage, $\mathrm{n}$ & 33 \\
PEG-associated mortality, $\mathrm{n}$ & 0 \\
\hline
\end{tabular}

Data presented as $n(\%)$ unless otherwise indicated

prophylaxis and 313 underwent full therapeutic anticoagulation with UFH, LMWH, and phenprocoumon with or without antiplatelet drugs. Twenty-nine patients were treated with antiplatelet drugs (clopidogrel or acetylsalicylic acid) alone.

Patients on UFH $(n=74)$ or phenprocoumon $(n=34)$ showed mean partial thromboplastin time target values of $50.2 \pm 17.5 \mathrm{~s}$ (range $37 \mathrm{~s}$ to $153 \mathrm{~s}$, reference range $23 \mathrm{~s}$ to $36 \mathrm{~s}$ ) and an INR of $1.5 \pm 0.7$ (range 1.2 to 5 , reference range 0.85 to 1.15 ), respectively. Twenty-one of the patients treated with phenprocoumon had an INR above $2.6(61.8 \%)$ at the time of PEG. Thirteen patients had an INR below 1.5. These patients were in the process of reaching the final therapeutic INR, with most being coanticoagulated with UFH or LMWH. Overall, the following INR ranges were seen: 1.16 to 1.5 (mean $1.3, \mathrm{n}=186$ ); 1.51 to 2 (mean 1.8, $\mathrm{n}=28$ ); and greater than 2 (mean 3.1, $\mathrm{n}=35$ ). Phenprocoumon-independent INR increases were due to liver disease, vitamin deficiency, malabsorption, penicillin, etc.

\section{Postoperative data}

In-hospital complications occurred in 141 patients (13.5\%). PEG was performed after a mean of 14.6 days (range one to 204 days). The mean hospitalization time was 27.4 days (range one to 268 days).

Table 3 summarizes the complications following PEG. The mean time to manifestation of peristomal infection was $6.7 \pm 10.4$ days (range one to 90 days). The infection rate was $11.1 \%$ (95\% CI 9.2\% to $13.1 \%$ [20.5\% in cancer patients and $5.5 \%$ in patients with nonmalignant diseases]; $\mathrm{P}>0.001$ ). Infection rates among patients undergoing antibiotic therapy at the time of PEG were not significantly different from those who were not $(9.8 \%$ versus $12.1 \% ; \mathrm{P}=0.23)$. Simple infections were treated with four to five dry dressing changes daily or, alternatively, with a hydrocellular wound dressing (eg, Allevyn, Smith \& Nephew, USA). Additional deep cleaning of the peristomal wound was performed every three days.

An additional jejunal extension tube was positioned via the PEG in 44 patients with protracted wound infection (peristomal skin expansion greater than $10 \mathrm{~mm}$ ). This measure improved drainage of gastric secretions, thereby circumventing gastric passage during enteral nutrition. Eleven patients received oral antibiotic therapy with a cephalosporin. The use of topical antibiotics is generally not undertaken in the department. The mean healing time of peristomal infections was $12.6 \pm 5.3$ days (range five to 26 days).

Peristomal bleeding $(0.5 \%$ [95\% CI $0.0 \%$ to $1.1 \%]$ ) occurred after a mean of $8 \pm 4.5$ days (range three to 14 days). There was no statistically significant difference between patients with or without anticoagulants, or in those with an increased INR (Table 1). In one case, bleeding from the peristomal gastric wall was found intraoperatively, with an unknown cause of coagulopathy but normal INR. In another case, traumatic bleeding from the gastric wall occurred after accidental PEG dislocation. In a further case, fatal hemorrhage from esophageal varices occurred as an unrelated event. This patient died during hospitalization from bleeding esophageal varices, which could not be

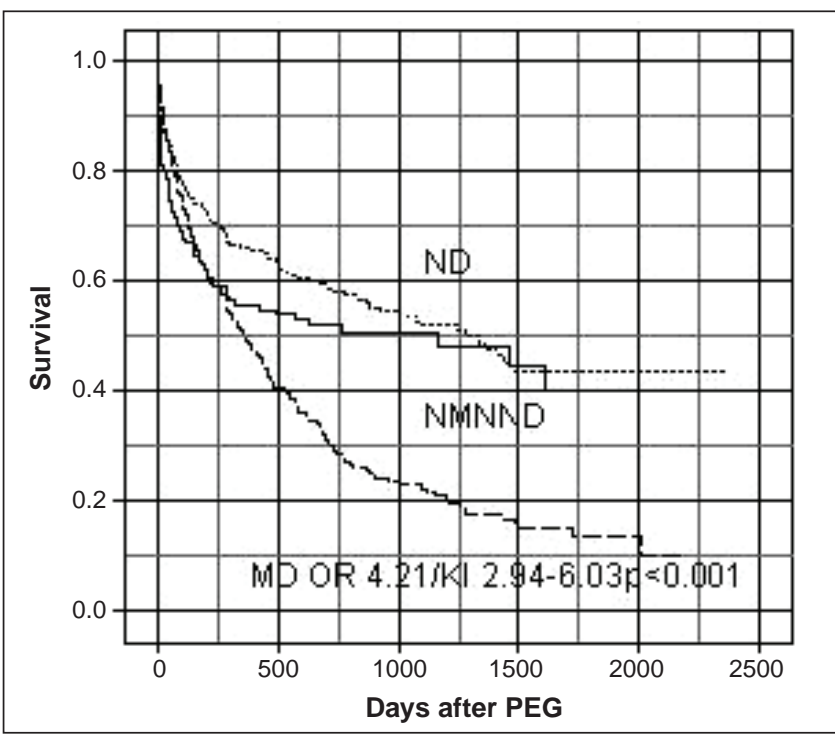

Figure 1) Kaplan-Meier plot of patients undergoing percutaneous endoscopic gastrostomy (PEG). MD Malignant diseases; ND Neurological diseases; NMNND Nonmalignant non-neurological diseases

controlled. In one patient with an INR of 1.2, the bleeding could not be definitively localized endoscopically, but stopped spontaneously. In a case involving an 18-month-old child, the bleeding stopped after compression of the gastric wall via the pressure plate.

Peritonitis requiring surgery was observed in 14 patients $(1.3 \%$ [ $95 \%$ CI $0.7 \%$ to $2.3 \%$ ]; mean $4.8 \pm 2.2$ days [range two to nine days]). Seven operations were performed due to traumatic dislocation of the PEG by the patient (mean $7 \pm 1.9$ days [range five to nine days]; nasooropharyngeal cancer $(n=3)$, neurological diseases $[n=4])$. In another seven cases (naso-oropharyngeal cancer $[n=4]$, other cancer $[n=1]$ and neurological disease $[\mathrm{n}=2])$, a chemical peritonitis without PEG dislocation (3.6 \pm 1.96 days [range two to seven days]) was present. In one of these cases, the greater omentum was caught between the stomach and abdominal wall. Intraoperatively, no aberrant punctures of the large or small intestine were found. In the univariate analysis, seven of the 14 risk factors were associated with a significantly elevated complication rate. Independent risk factors determined in multivariate analyses could only be evaluated for patients with PEG infections because of the insufficient number of events. A significantly elevated risk for post-PEG infection was found for patients with cancer or cirrhosis, and those with previous radiation exposure (Table 1).

\section{Follow-up}

The in-hospital PEG-independent mortality rate was 7.3\% (mean age $61 \pm 18.9$ years $[n=76])$. There was no procedure-related death. The mean follow-up was 1151 days (range 125 to 2371 days). The median post-PEG survival rates of patients with and without cancer are shown in Figure 1. Sixty-one of all patients died within 30 days (5.8\%). The 60 -day mortality rate was $18.9 \%$ and the total one-year mortality rate was $41.7 \%$. Significantly more patients with cancer died than patients without malignant diseases during the investigation period $(\mathrm{P}<0.001)$.

The PEG had been permanently removed after a mean of $6.7 \pm 8.8$ months (range 0.2 to 54.4 months) in 303 of 1041 patients (26.6\% with neurological diseases, $18.3 \%$ with naso-oropharyngeal cancer, $20.8 \%$ with other cancer and $52.9 \%$ with nonmalignant nonneurological diseases) because the patient was able to eat. In cases of PEG tube leakage or greatly shortened, blocked or buried bumper, PEG replacement was necessary after a mean of $9.5 \pm 2.6$ months (range seven to 14 months).

Surgical removal of the PEG was required in six patients with a buried bumper. No abdominal wall metastases were observed in patients with naso-oropharyngeal or other cancer during the observation period. 
After discharge, $69.6 \%$ (672 of 965 ) of patients required out-ofhospital care (during the follow-up period, $46.9 \%$ of whom required slight and $42.4 \%$ intensive care [according to the German Grading System for necessity of nursing care grades II and III, respectively]). Neurological diseases were present in 184 of these patients, while 101 had noncancer diseases. Due to artificial enteral feeding, 17.7\% $(\mathrm{n}=52)$ of patients reported diarrhea, and obstipation was seen in $12.6 \%(n=37)$. Transient vomiting and nausea was reported in 205 cases. In $61.9 \%$ of patients with neurological indications and $63.5 \%$ with other diseases, patients could maintain or even gain weight. This was possible, however, in only $35.4 \%$ of cancer patients.

\section{DISCUSSION}

Demographic trends show an increasing incidence of cardiovascular disease and cerebral ischemia. Therefore, it is not surprising that PEG placement using the pull/push and introducer methods has been established as the standard technique for enteral nutrition of elderly patients with multiple comorbidities. Cerebrovascular diseases (18\% to $35 \%)$, stroke, neurodegenerative and other neurological diseases $(40.7 \%$ to $23 \%$ ), as well as naso-oropharyngeal and other carcinomas (13.3\% to $17 \%)(5,6)$ are among the main indications for PEG in the United States and United Kingdom.

In our investigation, the in-hospital mortality and 30-day mortality rates were lower than those documented in several recent studies (7), in which mortality rates of between $15 \%$ and $32 \%$ were reported. This reflects the strict indication just as other authors suggest $(8,9)$. Otherwise, high long-term mortality of our patients is in agreement with previously reported rates of between $33 \%$ and $60 \%(10-12)$. These studies have consistently shown that cancer, older age and a high comorbitity index are risk factors for mortality after PEG.

Most of our patients also had multiple comorbidities, and more than three-quarters needed help - at least temporarily - with the application of artificial enteral feeding. Approximately 30\% of the patients did not tolerate artificial enteral feeding, which is comparable with previously reported data (10).

Slightly less than $50 \%$ of our noncancer patients required intensive care and were generally cared for in nursing homes, which may be one reason for the long survival (13).

On one hand, patients with neurological issues, especially cerebrovascular disorders, often require therapeutic anticoagulation in the acute phase over a longer period of time. Moreover, they have a greater risk of aspiration, as our data showed. Coupled with the expected protracted reconvalescence, early PEG placement would thus appear justified. On the other hand, the long-term risk of bleeding complications in patients on combination therapy with anticoagulants is five- to 7.4-fold higher $(14,15)$.

Thus, the international consensus suggests to discontinue this therapy five to nine days before PEG placement or to switch to acetylsalicylic acid monotherapy $(2,3)$. Nevertheless, in patients with high thromboembolic risks, such as serious atrial fibrillation, mechanical heart valve prosthesis, cerebrovascular insufficiencies, intracoronary or basilar stents, changing or stopping a treatment with anticoagulants could lead to life-threatening complications $(16,17)$. Due to this and the present paucity of data regarding periprocedural bleeding risk, the recommended indications for PEG are often made very conservatively.

The present study was the first to examine post-PEG complications in patients concurrently on anticoagulants. Comparable with the literature, our data showed that post-PEG bleeding was, generally, a rare event (12). However, no reliable information regarding the increased incidence of various PEG complications in patients with increased INRs and treated with anticoagulants are available.

One limitation of the present study is its relatively low predictive power due to the low incidence of post-PEG bleeding and the observational design. If we assumed a bleeding risk of approximately $1.6 \%$ in patients with PEG without anticoagulants, the necessary sample size would be 2400 patients per group (Fisher's test $1-\beta=0.80$, twosided significance level $\alpha=0.05$ ). With lesser risks, the numbers grow exponentially. However, we found post-PEG bleeding complications uniformly distributed in all patients without any increased bleeding risk in patients taking anticoagulants or with increased INR values. One possible explanation may lie in the PEG technique itself. Compared with other endoscopic high-risk procedures under anticoagulation, such as polypectomy, papillotomy or pancreaticogastrostomy, PEG not only has a short operation time, but also the smallest wound area, which is additionally compressed by the internal bumper and the external fixation plate at the procedures end.

The infection rates of $5 \%$ in patients with nonmalignant diseases and $20 \%$ in those with malignant diseases are consistent with infection rates reported in other studies. Wound infection using the pull-through method occurs in $5 \%$ to $36 \%$ of patients, despite the use of prophylactic antibiotic therapy (18-21). Moreover, Zopf et al (22) found that postPEG infection is significantly associated with risk factors such as underlying malignant diseases, tube size, institutional factors and endoscopist experience. Our data showed that cancer, previous radiation exposure and cirrhosis should be considered as additional significant risk factors of post-PEG infection. Patients, especially those with cancer, are often negatively influenced by additional immunosuppressing factors such as radio- or chemotherapy, or diabetes mellitus (23). In addition to increased vasoconstriction and damaged epithelium in the vascular wall, altered rheological properties of the blood and other hemodynamic influences due to cirrhosis, diabetes mellitus, or alcohol and nicotine abuse, are important factors in the pathogenesis of impaired wound and anastomosis healing (24), and can increase the risk of infection separately or in combination $(25,26)$. In the literature, different authors state that push methods such as percutaneous endoscopic gastrostomy $(27,28)$, or later methods such as the bumper-button type (29), have advantages in obese patients, decrease rates of wound infection and exclude stomal metastases. This could be beneficial for patients, especially those with oropharyngeal cancer. On the other hand, limitations of PEG include the the lack of possibility of diagnostic endoscopic examination and the higher risk for bleeding. In our experience, primarily in high-risk patients with portal hypertension or esophageal or gastric varices, only an intraluminal diagnostic examination during the procedure could query the indication. Furthermore, in patients with esophageal obstruction, the tumour can also be passed with a $5 \mathrm{~mm}$ endoscope - if not, the stenosis can easily be dilated to $8 \mathrm{~mm}$ to $10 \mathrm{~mm}$ without a relevant risk. This means that in most cases, the classical PEG pull-through technique can be performed endoscopically or assisted by computed tomography.

Lower costs, the involvement of only one operator, the speed of the procedure and no radiation exposure are the advantages and the reasons why the pull-through method for PEG is used in our department.

\section{SUMMARY}

The present study identified three risk factors that predict peristomal post-PEG infection: cancer, radiation exposure and cirrhosis. Taking this into consideration, our institution administers a single dose of antibiotic to patients at risk.

Despite the limitations of the present study, our data suggest that patients undergoing therapeutic anticoagulation or those with increased INR values have no elevated risk of bleeding during PEG placement. Therefore, in high-risk patients undergoing anticoagulation therapy or those with abnormal clotting, we neither defer PEG placement nor do we reverse anticoagulation (eg, fresh frozen plasma). If urgent enteral feeding is necessary, we perform the procedure with the relevant anticoagulants.

Furthermore, secondary complications such as difficulties in reestablishing warfarin or phenprocoumon therapy after overaggressive reversal with vitamin $\mathrm{K}$ before PEG placement can be avoided.

Endoscopic examination and PEG placement in anticoagulated patients using a one-handed video-assisted or fiberoptic technique should, nonetheless, be performed only by experienced specialists. The majority of complications occur within the first week, and daily clinical assessment by the endoscopist or a trained member of the team should be performed during the first eight days. 


\section{REFERENCES}

1. Löser Chr, Aschl G, Hebuterne X, et al. ESPEN guidelines on artificial enteral nutrition-percutaneous endoscopic gastrostomy (PEG). Clinical Nutrition 2005;24:848-61.

2. Eisen GM, Baron TH, Dominitz JA. ASGE guideline on the management of anticoagulation and antiplatelet therapy for endoscopic procedures. Gastrointestinal Endoscopy 2002;55:775-9.

3. Zuckermann MJ, Hirota WK, Adler DG. ASGE guideline: The management of low-molecular-weight heparin and nonaspirin agents for endoscopic procedures. Gastrointest Endosc 2005;61:189-94.

4. Gauderer MW, Ponsky JL, Izant RJ. Gastrostomy without laparotomy: A percutaneous endoscopic technique. J Pediatr Surg 1980;15:872-5.

5. Callahan CM, Haag KM, Weinberger M, et al. Outcomes of percutaneous endoscopic gastrostomy among older adults in a community setting. J Am Geriatr Soc 2000;48:1048-54.

6. Elia M, Russell CA, Stratton RJ, eds. In: British Artificial Nutrition Survey (BANS) report. Trends in artificial nutrition support in the UK during 1996-2000. Redditch: British Association for Parenteral Nutrition (BAPEN), 2001.

7. Lowry S, Johnston SD. Who follows up patients after PEG tube insertion? Ulster Med J 2007;76:88-90.

8. Niv Y, Abuksis G. Indications for percutaneous endoscopic gastrostomy insertion: Ethical aspects. Dig Dis 2002;20:253-6.

9. Stroud M, Duncan H, Nightingale J. Guidelines for enteral feeding in adult hospital patients. Gut 2003;52(Suppl 7):vii1-vii12.

10. Löser C, Wolters S, Fölsch UR. Enteral long term nutrition via percutaneous endoscopic gastrostomy in 210 patients: A four year prospective study. Dig Dis Sci 1998;43:2549-57.

11. Figueiredo FAF, Costa MC, Pelosi AD, et al. Predicting outcomes and complications of percutaneous endoscopic gastrostomy. Endoscopy 2007;39:333-8.

12. Smith BM, Perring P, Engoren M, et al. Hospital and long-term outcome after percutaneous endoscopic gastrostomy. Surg Endosc 2008;22:74-80.

13. Rimon E, Kagansky N, Levy S. Percutaneous endoscopic gastrostomy, evidence of different prognosis in various patient subgroups. Age and Aging 2005;34:353-5.

14. Hallas J, Dall M, Andries A, et al. Use of single and combined antithrombotic therapy and risk of serious upper gastrointestinal bleeding: A population-based case-control study. BMJ 2006;333:726-9.
15. Leon MB, Baim DS, Popma JJ, et al. A clinical trial comparing three antithrombotic-drug regimes after coronary-artery stenting. N Engl J Med 1998;339:1665-71.

16. Blacker DJ, Wijdicks EFM, McClelland RL. Stroke risk in anticoagulated patients with atrial fibrillation undergoing endoscopy. Neurology 2003;61:964-8.

17 Cannegieter SC, Rosendaal FR, Briet E. Thromboembolic and bleeding complications in patients with mechanical heart valve prosthesis. Circulation 1994;89:635-41.

18. Faias S, Cravoi M, Claro I, et al. High rate of percutaneous endoscopic gastrostomy site infections due to oropharyngeal colonization. Dig Dis Sci 2006;51:2384-8.

19. MacClave SA, Chang WK. Complications of enteral access. Gastrointest Endosc 2003;58:739-51.

20. Gossner L, Keymling J, Hahn EG, Ell C. Antibiotic prophylaxis in percutaneous endoscopic gastrostomy (PEG). A prospective randomized clinical trial. Endoscopy 1999;31:119-24.

21. Sangster W, Cuddington GD, Bachulis BL. Percutaneous endoscopic gastrostomy. Am J Surg 1988;155:677-9.

22. Zopf Y, Konturek P, Nuernberger A, et al. Local infection after placement of percutaneous endoscopic gastrostomy tubes: A prospective study evaluating risk factors. Can J Gastroenterol 2008;22:987-91.

23. Lee L, Kim J, Kim Y, et al. Increased risk of peristomal wound infection after percutaneous endoscopic gastrostomy in patients with diabetes mellitus. Digest of Liver Disease 2002;34:857-61.

24. Sorensen Lt, Jorgensen T, Kirkeby Lt, et al. Smoking and alcohol abuse are major risk factors for anastomotic leakage in colorectal surgery. Br J Surg 1999;86:927.

25. Meiselman H, Baskurt OK. Hemorheology and hemodynamics: Dove and dare? Clin Hemorheol Microcirc 2006;35:37-43.

26. Darouiche RO. Device-associated infection: A macroproblem that starts with microadherence. Clin Infect Dis 2001;33:1567-71.

27. Shaw AS, Ampong MA, Rio A, et al. Entristar skin-level gastrostomy tube: Primary placement with radiologic guidance in patients with amyotrophic lateral sclerosis. Radiology 2004;233:392-9.

28. Given MF, Hanson JJ, Lee MJ. Interventional radiology techniques for provision of enteral feeding. Cardiovasc Intervent Radiol 2005;28:692-703.

29. Horiuchi A, Nakayama Y, Tanaka N, et al. Prospective randomized trial comparing the direct method using a 24 Fr bumper-button-type device with the pull method for percutaneous endoscopic gastrostomy. Endoscopy 2008;40:722-6. 


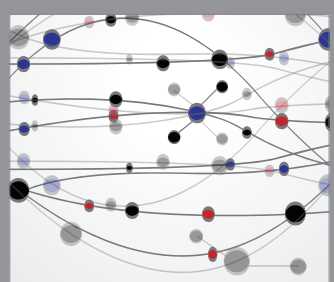

The Scientific World Journal
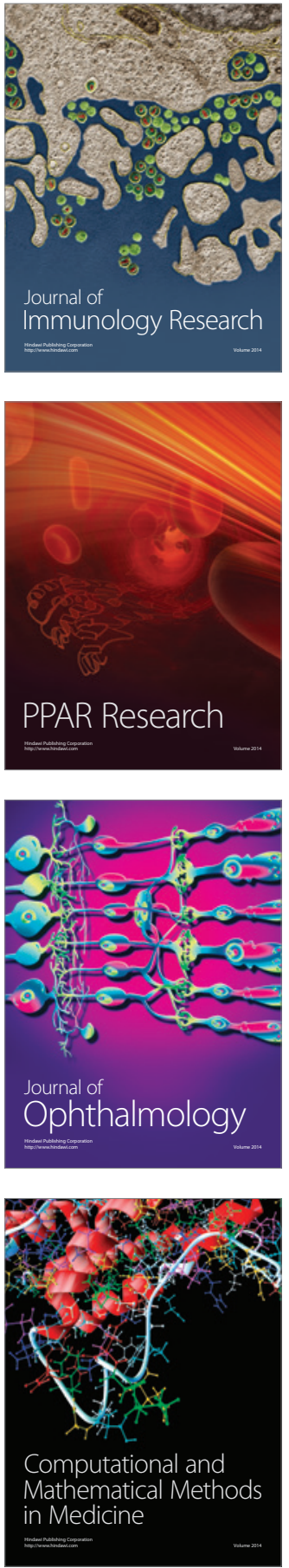

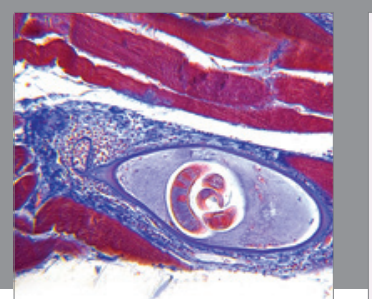

Gastroenterology Research and Practice

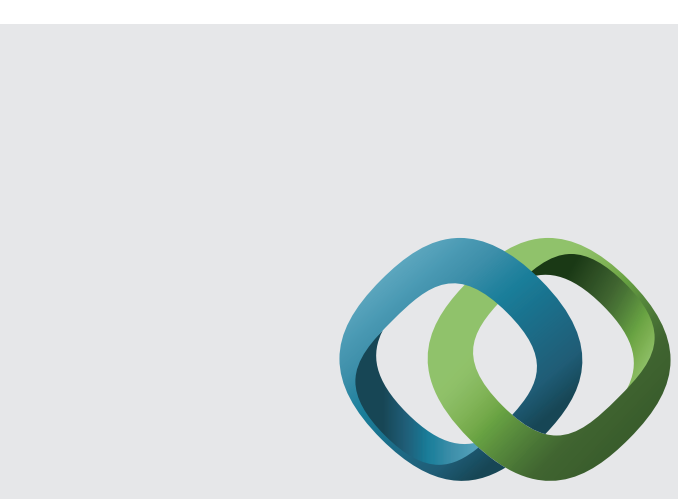

\section{Hindawi}

Submit your manuscripts at

http://www.hindawi.com
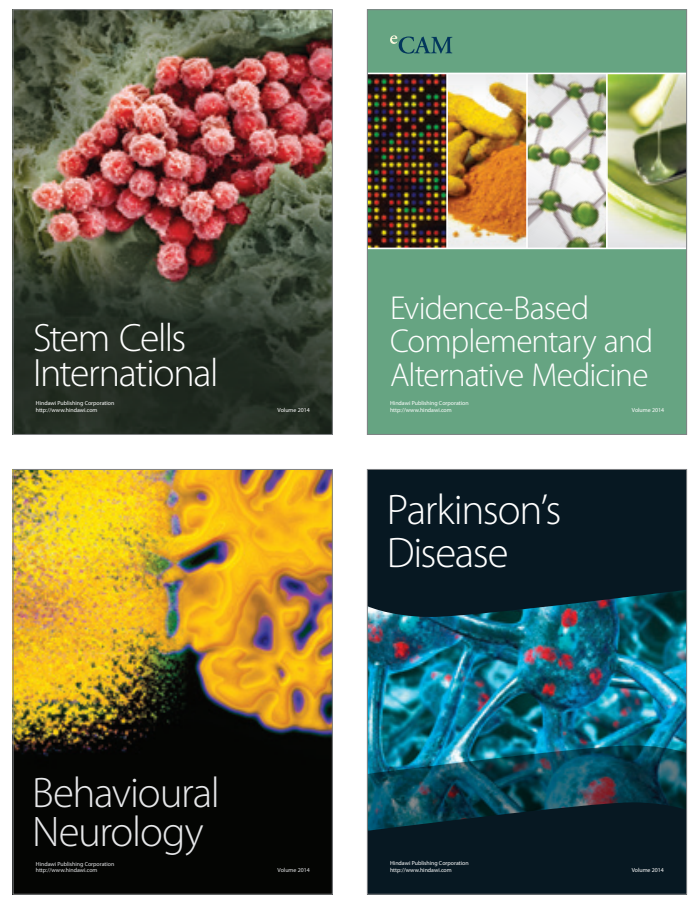
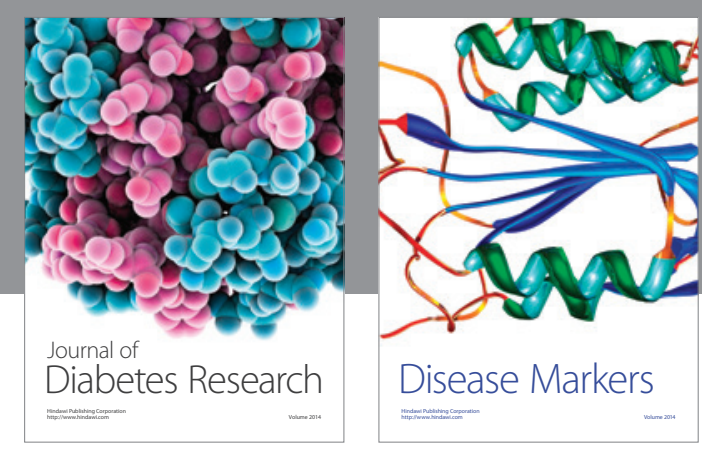

Disease Markers
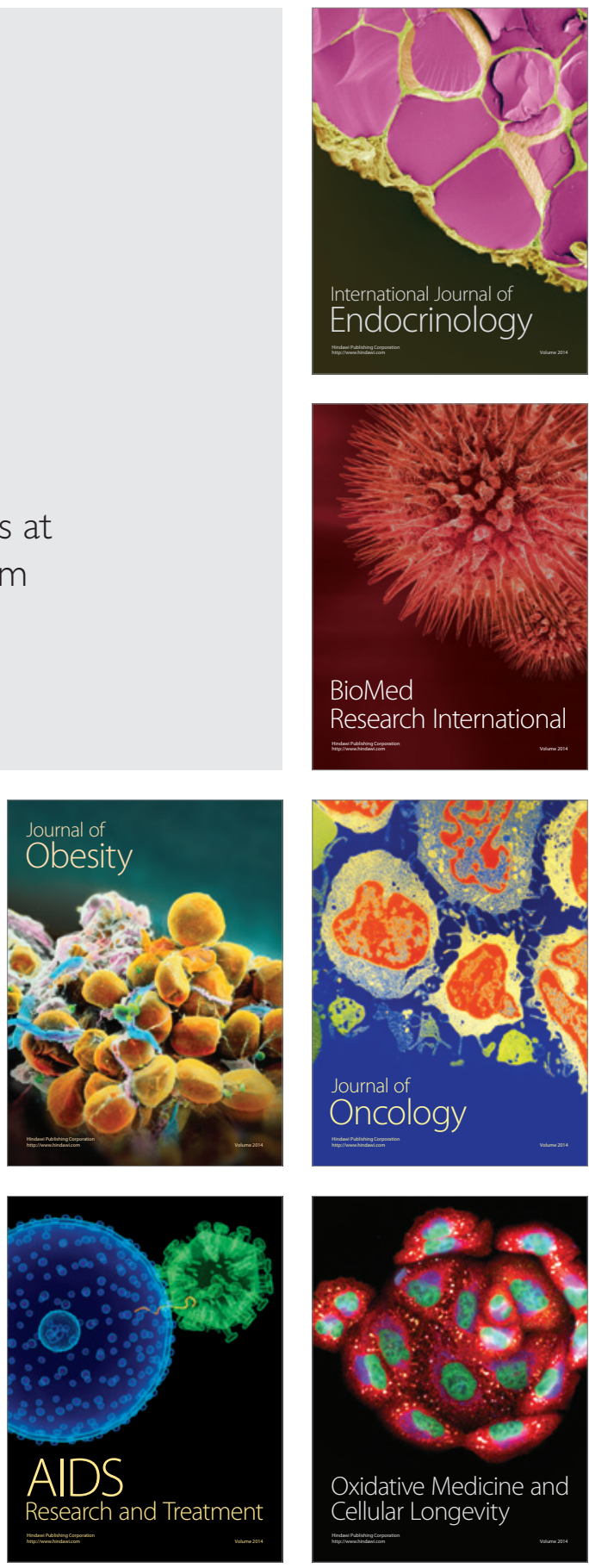